\title{
Imobilização de Proteínas do Veneno do Escorpião Tytius Serrulatus em Blenda Condutora de Polianilina-Poli(Metacrilato de Hidroxietila)
}

\author{
Lívio Bruno, Guilherme Barra, Herman Mansur, Rodrigo L. Oréfice \\ Departamento de Engenharia Metalúrgica e de Materiais, UFMG
}

\begin{abstract}
Resumo: Biossensores têm a função de detectar e analisar tanto quantitativa como qualitativamente a presença de uma certa molécula em um determinado meio, isto com resposta em tempo real e sem etapas intermediárias de processo. Para isso, o biossensor possui sempre em seu conjunto um sistema de reconhecimento biológico que o diferencia de qualquer outro tipo de sensor. O objetivo deste trabalho foi desenvolver hidrogéis condutores a partir da combinação de polianilina com hidrogel poli(metacrilato de hidroxietila) e avaliar alguns aspectos associados à possível utilização deste como base de um biossensor capaz de detectar a presença de frações tóxicas do antígeno do veneno do escorpião Tytius Serrulatus. Hidrogéis condutores foram sintetizados a partir da mistura, em diferentes proporções, de polianilina e poli(metacrilato de hidroxietila) em um solvente comum. A condutividade elétrica (método de quatro pontas), capacidade de inchamento e morfologia (microscopia eletrônica de varredura) foram avaliadas para blendas com diferentes composições. Antígenos relativos ao veneno do escorpião Tytius Serrulatus foram incorporados às blendas condutoras a partir do inchamento dos hidrogéis por soluções aquosas contendo as moléculas de interesse. A imobilização e bioatividade das biomacromoléculas nos hidrogéis foram constatadas através de ensaio imunoabsorvente ELISA cujos resultados foram avaliados por espectroscopia na região do ultravioleta-vísivel. Os resultados mostraram que a incorporação de baixos conteúdos de Pani (20\% em massa) em hidrogéis de poli(metacrilato de hidroxietila) foi suficiente para a produção de materiais com elevada condutividade elétrica e grande capacidade de inchamento. Moléculas associadas ao veneno do escorpião Tytius Serrulatus foram imobilizadas com sucesso nos hidrogéis condutores e mantiveram suas capacidades funcionais.
\end{abstract}

Palavras-chave: Biossensor, polianilina, blendas condutoras, escorpião.

\section{Proteins Associated with the Venom of the Tytius Serrulatus Scorpion Immobilized within Polyaniline-Poly(Hydroxyethyl Methacrylate) conducting blends}

Abstract: Biosensors can detect and analyze quantitatively and qualitatively the presence of a given molecule in a specific environment. Biosensors always have a biological recognition system that distinguishes them from any other kind of sensor. The goals of this work were to develop conductive hydrogels from the combination of polyaniline and poly(hydroxyethyl methacrylate) and to evaluate some important aspects related to the possibility of using these materials as matrices in biosensors that would detect toxic fractions of antigens associated with the venom of the Tytius Serrulatus scorpion. Different conductive blends from poly(hydroxyethyl methacrylate) and polyaniline were produced by dissolving the polymers in a common solvent. The electrical conductivity, morphology and swelling ability were measured the four-probe measuring system, scanning electron microscopy and weight gain in water, respectively. Immobilization and bioactivity of molecules associated with the venom of the Tytius Serrulatus scorpion were evaluated by combining the ELISA immunoassay method and ultraviolet-visible spectroscopy. The results showed that even low concentrations of polyaniline led to high values of electrical conductivity and swelling. The biological tests indicated that the immobilization and bioactivity of the biomacromolecules associated with the venom of the Tytius Serrulatus scorpion were successfully achieved within the conductive hydrogel.

Keywords: Biosensor, polyaniline, conductive blends, scorpion.

\section{Introdução}

Um biossensor é um aparato de detecção de moléculas com características singulares. Ele possui uma estrutura dividida em três partes como na Figura 1. A primeira é responsável pela detecção e é formada por uma biomolécula com suas funções biológicas ativas imobilizada numa matriz que lhe serve de base física e proteção contra desnaturação. A segunda parte é constituída de um transdutor de sinais que funciona como um estágio que interpreta os eventos biológicos, ocorridos na etapa de detecção, e os transforma em sinais eletrônicos. A terceira parte diz respeito à saída de dados

Autor para correspondência: Rodrigo L. Oréfice, Laboratório de Engenharia de Polímeros e Compósitos, Departamento de Engenharia Metalúrgica e de Materiais, UFMG, Rua Espírito Santo 35/206, CEP: 30160-030, Belo Horizonte, MG. E-mail: rorefice@demet.ufmg.br 


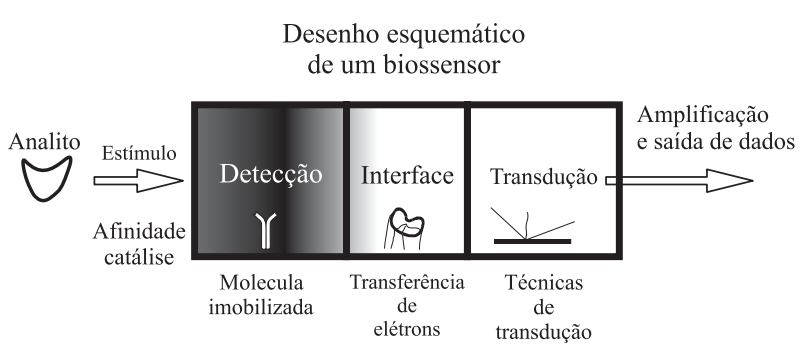

Figura 1. Esquema de um biossensor segundo Caruso ${ }^{[1]}$.

que modela os sinais eletrônicos do transdutor para os tornar legíveis em uma interface humana qualquer como um medidor, um display ou tela de computador ou laptop. Apesar do biossensor não possuir ainda uma definição padrão poderemos resumir todo o esquema supramencionado com a definição dada por CARUSO (1997): “ O consenso daqueles que trabalham no campo do biosensoriamento é que o biossensor é um aparato analítico que explora a detecção biológica ou sistema de reconhecimento para a uma molécula ou biomolécula alvo, em conjunção com um transdutor fisico-químico, que converte o evento de reconhecimento biológico em um sinal de saída utilizável"[1]. Segundo LUPPA (2001) o imunossensor é uma variação de um biossensor ${ }^{[2]}$.

Nos últimos anos, os biossensores foram propostos para participarem em uma série de aplicações em diversas áreas. Pode-se citar algumas como:

- Diagnóstico clínico - Hoje o diagnóstico clínico depende da análise bioquímica que passa por várias etapas que podem ser eliminadas com o uso de biossensores, pois quanto mais cedo se identifica uma certa patologia mais fácil é de tratá-la. Os biossensores dão diagnóstico em tempo real.

- Monitoramento intensivo da saúde - Tal fato é muito importante para pacientes que estão sob cuidados intensivos, e por isso a resposta imediata de qualquer variação do quadro clínico é vital.

- Industria de alimentos - Para identificar qualquer tipo de contaminação no armazenamento e processamento é necessária uma detecção precisa de agentes que possam ameaçar a saúde.

- Controle do meio ambiente - Os biossensores também são úteis no monitoramento contra gases tóxicos perto ou dentro de indústrias que oferecem perigo ou mesmo ambientes suscetíveis a grandes cargas de poluição urbana.

- No controle de infecções hospitalares e salas limpas Tanto em indústrias, como a de semicondutores, quanto em ambientes hospitalares o controle de partículas e agentes de infecção é importante papel que pode ser desempenhado pelos biossensores.

- Defesa da população civil - Devido às ameaças de armas biológicas e químicas do terrorismo internacional, é indispensável agentes de detecção como os biossensores para a defesa da população exposta a esse tipo de situação, como ocorreu recentemente com o bacillus antracis (Antrax) nos Estados Unidos. Em vista disso, em seu plano de combate ao terrorismo, o governo americano dispensou recentemente

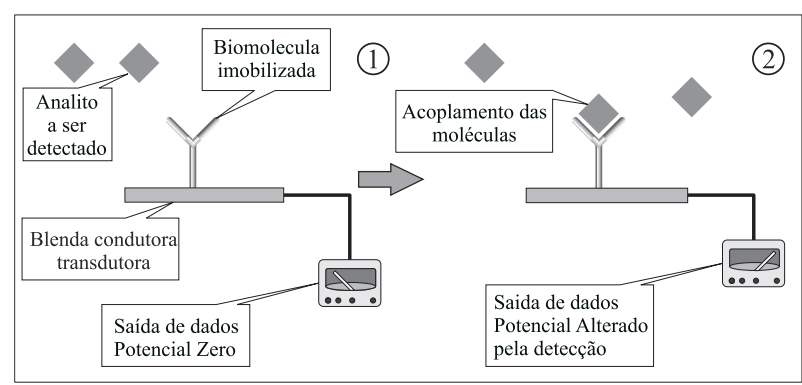

Figura 2. Monitoramento Eletrônico do acoplamento das moléculas.

vários milhões de dólares para pesquisa de formas de detecção destes tipos de arma, incluindo os biossensores.

Um dos materiais que vem sendo testados na formulação de biossensores são as blendas formadas por polímeros condutores, que transmitem e amplificam sinais eletrônicos, combinados com outros que possuem boa afinidade com moléculas biológicas ${ }^{[3,4]}$. O objetivo principal é proporcionar um sítio favorável a imobilização de biomoléculas sem que aconteça a sua desnaturação fisiológica. O segundo objetivo é desempenhar a função de transdução e emissão de dados. Na prática, a proposta se resume em monitorar a mudança do potencial eletrônico que ocorre quando a biomolécula imobilizada se acopla ou reage com sua molécula específica correspondente (analito), como numa ligação chave fechadura. A Figura 2 ilustra a essência do processo.

Nessa investigação, propõe-se a verificação da capacidade da blenda condutora constituída pelos polímeros poli(metacrilato de hidroxietila) (PHEMA) e polianilina (Pani) em absorver e reter em sua estrutura a conjugação de proteínas formadas pela fração tóxica do antígeno do veneno do escorpião Tytius Serrulatus bem como seu anticorpo correspondente. O objetivo dessa avaliação é produzir um substrato condutor de eletricidade e imobilizador de biomoléculas que servirá de transdutor e elemento detector respectivamente para um futuro biossensor que vai medir a concentração de veneno desse escorpião em um determinado meio. Um dispositivo como esse é extremamente necessário em vista das estatísticas das ocorrências de picadas desse tipo de escorpião em Minas Gerais e em outras partes do Brasil. O Tytius Serrulatus é responsável por cerca de 10.000 casos anuais, notificados oficialmente nas zonas rurais, com taxa de mortalidade de $1,1 \%$, na sua maioria de crianças ${ }^{[5]}$.

Até o momento, o método usado para identificação deste tipo de veneno tem sido ensaios imunohistoquímicos ${ }^{[6]}$. Esses ensaios apresentam normalmente algumas dificuldades, como longo tempo de realização e as muitas etapas de processo. O monitoramento eletrônico da interação entre antígeno e anticorpo relacionado a esse veneno favorecerá o diagnóstico rápido da picada desse escorpião. Isso facilita o tratamento do paciente ao identificar a quantidade de veneno bem como sua imunidade natural ao mesmo, permitindo a definição da dosagem da medicação a ser administrada. Tudo isso aumenta significativamente as chances de recuperação.

A escolha a priori de blendas condutoras como base na formulação de biossensores se justifica pela potencial capaci- 
dade de combinar condutividade elétrica (oriunda dos polímeros condutores) com habilidade de interagir com soluções aquosas contendo biomacromoléculas (hidrogéis). É reportado em literatura que polímeros condutores ${ }^{[7]}$, em geral, como a Pani, são potenciais ideais candidatos a participarem na formulação de biossensores ${ }^{[8]}$. Da mesma maneira, o PHEMA é bastante utilizado como matriz para imobilização de proteínas ${ }^{[9]}$. Sendo um hidrogel, o PHEMA forma uma rede que encapsula em sua estrutura as biomoléculas presentes na solução em que está exposto através do fenômeno de inchamento. Além disso, o inchamento do hidrogel disponibiliza sítios contendo a biomolécula imobilizada, o que permite maior oportunidade para interação entre a molécula imobilizada e aquela que pretende ser detectada (aumento da sensibilidade de detecção).

Neste trabalho, as duas características evidentes destes dois polímeros, isto é, a boa capacidade de imobilização e a possibilidade de transdução de sinal, foram consideradas para produzir uma blenda a qual será base na formulação de um futuro biossensor.

\section{Experimental}

\section{Síntese dos polímeros}

A polianilina foi sintetizada segundo o protocolo de McDiarmid et $\mathrm{al}^{[10]}$. Este método consiste na obtenção da polianilina, utilizando-se um excesso de anilina, onde a razão molar entre o agente oxidante, persulfato de amônio (APS) e a anilina (Ani) foi de 0,25. A anilina utilizada foi previamente destilada sob vácuo. O PHEMA foi sintetizado através da polimerização radicalar do monômero 2-metacrilato de hidroxietila tendo como iniciador o 4,4-Azo Bis (4 ácido cianovalérico) (Aldrich) em etanol 95\%. O meio da reação foi mantido à $80^{\circ} \mathrm{C}$ por 90 minutos. Após a síntese, o solvente foi retirado com vácuo dinâmico.

\section{Síntese das blendas}

Os dois polímeros previamente sintetizados foram misturados em solvente comum, no caso o dimetil sulfóxido (DMSO). A mistura em proporções diferentes de Pani e PHEMA foi mantida a $80{ }^{\circ} \mathrm{C}$ por 30 minutos e depois quantidades diferentes de agente reticulante diclohexil-4,4 diisocianato (MDI) foram adicionadas à mistura para criar as ligações cruzadas. $\mathrm{O}$ agente reticulante MDI reage os grupos hidroxila do PHEMA formando ligações cruzadas do tipo uretano entre as cadeias poliméricas. A mistura foi vazada em placas de Teflon ${ }^{\circledR}$ onde ocorreu a evaporação do solvente e a formação de filmes da blenda. Depois de secas, as blendas foram colocadas em uma solução de $1 \mathrm{M}$ de $\mathrm{HCl}$ para a protonação.

\section{Imobilização das proteínas e ensaio ELISA}

As proteínas, a serem imobilizadas nas blendas, foram dosadas em sua concentração segundo o método de Lowry ${ }^{[1]]}$. Amostras de blendas, na forma de filmes com a massa em torno de 3,0 mg, foram expostas à soluções contendo frações tóxi- cas de antígenos relacionados com o veneno do escorpião Tytius Serrulatus. Tais frações do veneno, assim como os respectivos anticorpos, foram extraídos, purificados e produzidos no Instituto de Ciências Biológicas da UFMG ${ }^{[5]}$. As soluções tinham as concentrações de $10 \mu \mathrm{g} / \mathrm{mL}$ para os anticorpos e $100 \mathrm{ng} / \mathrm{ml}$ para as frações do antígeno em solução de tampão de incubação. Em cada uma das soluções, as amostras obedeceram ao seguinte procedimento: imersão por uma hora em temperatura de $37^{\circ} \mathrm{C}$ e posteriormente overnight a $4{ }^{\circ} \mathrm{C}$. Após cada imobilização, as blendas foram exaustivamente lavadas em solução de lavagem para eliminação de resíduos que foram agregados com o procedimento anterior. Após esse procedimento, as amostras foram submetidas ao imunoensaio ELISA. Esse ensaio consiste em expor a molécula imobilizada (antígeno) ao seu anticorpo para viabilizar uma ligação específica entre os dois, tipo chave e fechadura. Depois disso, caracteriza-se esse bioevento com outro anticorpo marcado com uma peroxidase, que absorve na região do visível, e que por isso pode ser monitorada pela espectroscopia na região do visível. O ensaio ELISA foi feito segundo protocolo de Olórtegui ${ }^{[6]}$. Posteriormente, a intensidade dessa coloração, que revela a quantidade de ligações, pôde ser quantificada por uma espectroscopia na região do ultravioleta-visível. A Figura 3 mostra um desenho esquemático de um ensaio ELISA.

\section{Caracterização}

\section{Ensaio de inchamento}

A estrutura em rede dos hidrogéis de PHEMA tem como característica reter grandes quantidades de água ou fluidos biológicos, provocando uma variação dimensional no material que é denominado como inchamento. O inchamento (swelling) tem sido muito usado para imobilizar biomoléculas sem danificá-las. Depois de sintetizadas, as blendas secas foram

ELISA Sanduíche

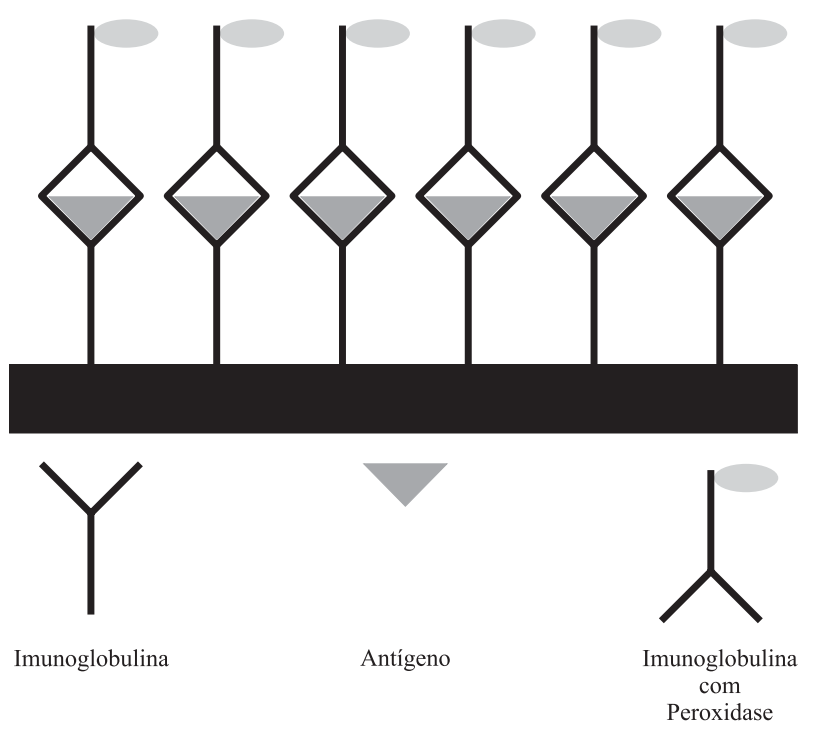

Figura 3. Esquema ilustrativo do imunoensaio ELISA sanduíche no material $(\mathrm{IgG}=$ imunoglobulina $\mathrm{G}=$ anticorpo $)$. 
pesadas após serem mergulhadas por 24 horas em água destilada. Antes do ensaio de inchamento, as amostras foram submetidas a um processo de extração em água visando a eliminação de eventuais resíduos remanescentes da síntese dos polímeros. A estabilização da massa durante a extração foi usada como indicação da eliminação completa dos resíduos não acoplados aos polímeros.

\section{Ensaio de condutividade}

Ensaios de condutividade foram feitos através do método de quatro pontas. Para amostras de baixa resistividade foi usado o Eletrômetro Keithley 224 A, para alta resistividade foi empregado o Eletrômetro Keith 617. Amostras com diversas proporções de Pani em PHEMA tiveram condutividade elétrica avaliada.

\section{Microscopia eletrônica de varredura}

A microscopia eletrônica de varredura (MEV) foi utilizada para investigar o grau de homogeneidade do material. É importante observar que a Pani deve estar bem dispersa na mistura para fornecer valores elevados de condutividade elétrica. O equipamento utilizado foi o JSM-5410 da JEOL ${ }^{\circledR}$. Todas as amostras foram observadas com um aumento de 2000X e, antes de serem observadas, foram metalizadas com uma fina camada de ouro. Foram observadas a superfície natural dos materiais e também as regiões de fratura geradas nas amostras.

\section{Espectroscopia na região do ultravioleta-visível para amostras sólidas}

A espectroscopia na região do ultravioleta-visível foi usada para indicar a presença e bioatividade das proteínas associadas ao veneno de escorpião ligadas na estrutura dos materiais. A comparação do material não submetido à imobilização de proteínas e outro passando por esse procedimento e também pelo teste ELISA permite a princípio, acompanhar os processos de imobilização das proteínas na blenda e a interação antígeno-anticorpo.

\section{Resultados e Discussão}

\section{Ensaio de Inchamento}

A Figura 4 mostra os resultados dos ensaios de inchamento para blendas Pani-PHEMA com diferentes proporções entre os polímeros. Este resultado demonstra que MDI se mostrou bem sucedido como agente reticulante do sistema, quando usado em uma concentração igual a 5\% em massa de PHEMA. A introdução progressiva de Pani no hidrogel de PHEMA reduziu significativamente os valores de inchamento, evidenciando a reduzida contribuição da Pani para a impregnação das blendas por fluidos aquosos. A combinação de Pani e PHEMA em um reticulado semi-interpenetrante permitiu alcançar valores elevados de inchamento que a priori podem favorecer uma mais eficiente interação entre polímeros e biomacromoléculas, resultando numa maior eficiência de detecção para um eventual biossensor.

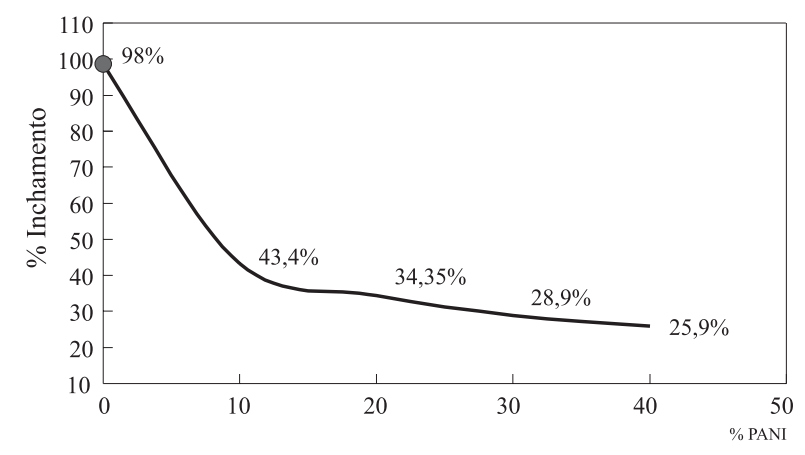

Figura 4. Gráfico da variação do inchamento de blendas Pani-PHEMA em relação porcentagem em massa de Pani, para um mesmo valor de agente reticulante $(5 \%)$ presente no PHEMA.

\section{Morfologia das blendas: microscopia eletrônica de varredura}

As fotomicrografias das Figura 5 e 6 mostram as superfícies natural e de fratura para blendas com diferentes conteúdos de Pani. O grau de homogeneidade de distribuição dos
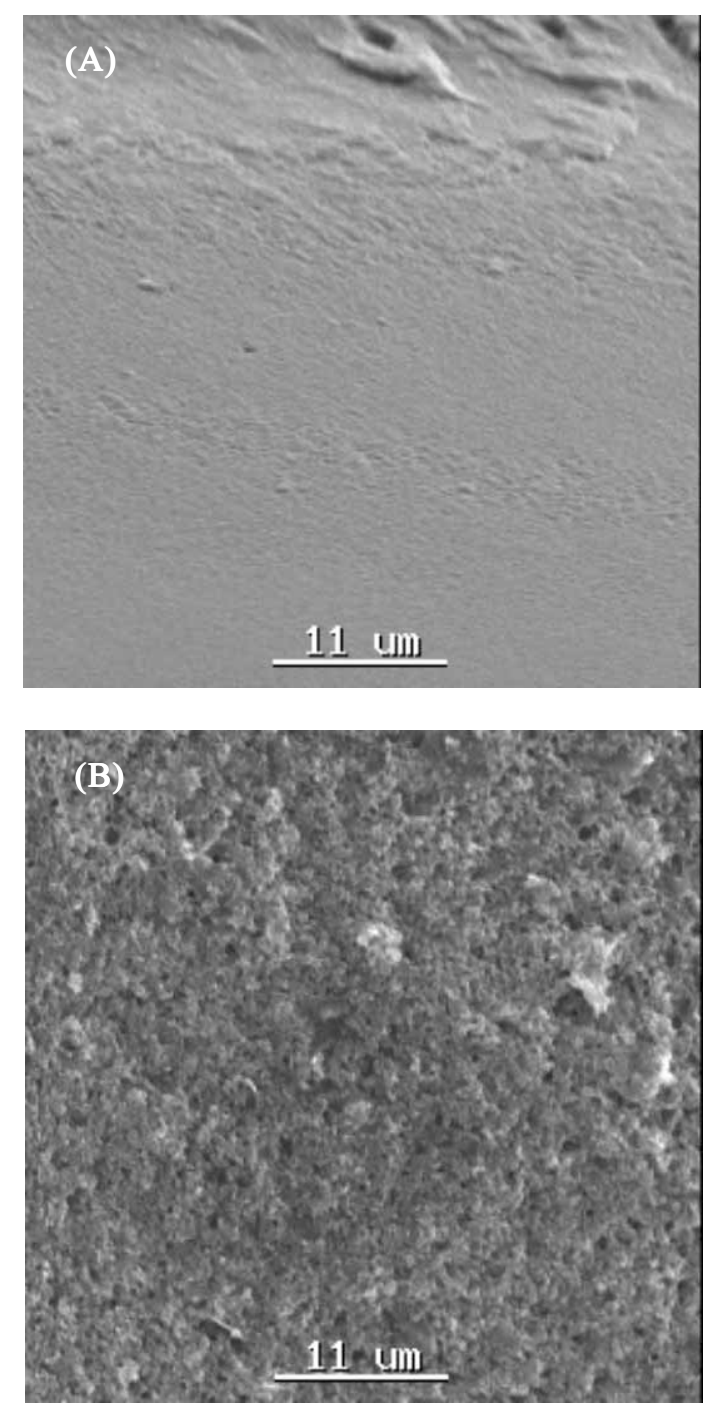

Figura 5. Fotomicrografia da Blenda PHEMA $80 \%$-Pani 20\%. (A) Superfície de fratura e (B) superfície natural (2000 X). 

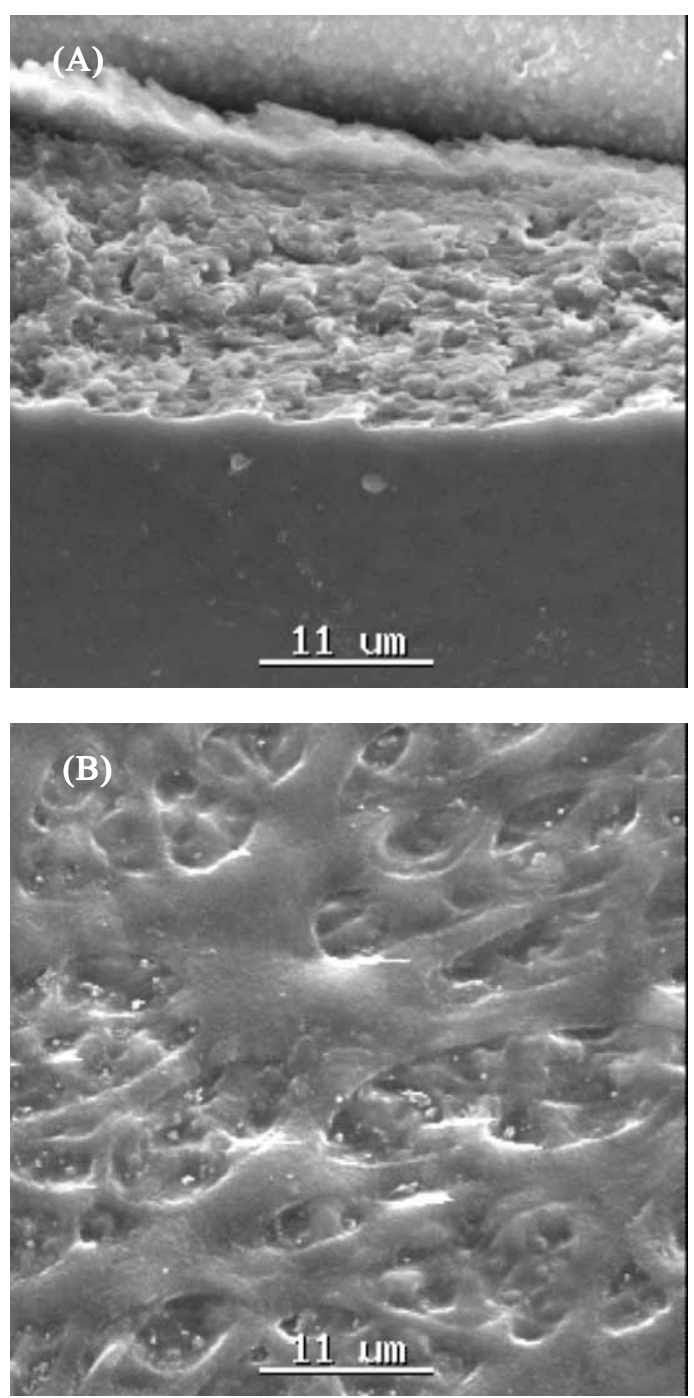

Figura 6. Fotomicrografia da Blenda PHEMA 50\%-PANI 50\%. (A) Superfície de fratura e (B) superfície natural $(2000 \mathrm{X})$.

componentes da blenda permite avaliar o nível de interação entre os polímeros obtidos durante a síntese. Separação de fase em níveis macro ou microscópicos pode resultar em instabilidade dimensional e mecânica durante o inchamento da blenda em contato com soluções aquosas contendo proteínas. Além disso, macro ou micro-segregações entre os componentes da blenda podem resultar em reduzida condutividade elétrica, caso não haja conectividade entre os domínios ricos no polímero condutor (Pani). Os resultados de microscopia eletrônica de varredura mostraram que para as amostras com até $20 \%$ de Pani (Figura 5), e no aumento de 2000x, foi impossível identificar os domínios ricos em PHEMA ou Pani, indicando um grau de homogeneidade elevado. Para composições acima de $25 \%$ de Pani, domínios ricos de Pani se tornam mais evidentes (porções mais escuras nas micrografias), sugerindo um processo de separação de fase mais severo.

\section{Ensaio de condutividade}

Medidas de condutividade elétrica da blenda para várias proporções de PHEMA e Pani foram realizadas usando o
Tabela 1. Medidas de condutividade das amostras PHEMA puro, blenda PHEMA-Pani e Pani pura.

\begin{tabular}{cc}
\hline $\begin{array}{c}\text { Pani.HCl } \\
(\boldsymbol{\%})\end{array}$ & $\begin{array}{c}\text { Condutividade Elétrica } \\
(\mathbf{S} / \mathbf{c m})\end{array}$ \\
\hline 0 & $1.4 \times 10^{-14}$ \\
5 & $3.2 \times 10^{-5}$ \\
10 & $4.4 \times 10^{-5}$ \\
20 & $1.4 \times 10^{-3}$ \\
40 & $1.0 \times 10^{-3}$ \\
50 & $2.2 \times 10^{-2}$ \\
100 & $3.2 \times 10^{-2}$ \\
\hline
\end{tabular}

método de quatro pontas. O objetivo foi relacionar a condutividade com valores aceitáveis de inchamento das blendas. Conforme pode ser observado pela Tabela 1, a blenda atinge um valor de condutividade elétrica próxima à Pani reprotonada com $\mathrm{HCl}$, para a concentração de $50 \%$ em massa. O limiar de percolação das blendas foi calculado a partir da teoria de percolação, resumida na equação $1^{[12,13]}$.

$$
\sigma_{f}=c\left(f-f_{p}\right)^{t}
$$

Onde c é uma constante, t o expoente crítico, f a fração volumétrica do polímero condutor e $\mathrm{f}_{\mathrm{p}}$ corresponde a fração volumétrica do polímero condutor no limiar de percolação. Neste trabalho, o limiar de percolação foi expresso em termos da massa do polímero condutor (Pani).

Com os resultados da Tabela 1 foi feita uma curva de log $\sigma$ versus $\log (\mathrm{f}-\mathrm{fp})$. Os valores de fp e $\mathrm{t}$ foram respectivamente de 0,4 e 2,0, apresentando um coeficiente de correlação de 0,98 . Segundo a teoria clássica da percolação, o expoente crítico $(t)$ representa o número médio de contatos por partícula na concentração crítica e seu valor deve estar entre $1,5 \mathrm{e}$ 2,0 . O limiar de percolação deste sistema $(0,4)$ pode ser considerado como um excelente resultado obtido quando comparado com a literatura ${ }^{[13,14]}$.

\section{Espectroscopia na região do ultravioleta-visível: determinação da interação entre biomacromoléculas e blendas condutoras}

Após a imobilização de antígenos relacionados com o veneno do escorpião Tytius Serrulatus, foi usada a espectroscopia na região do ultravioleta-visível por reflexão para investigar o evento da imobilização e bioatividade das biomoléculas. Tais aspectos foram realçados através do emprego do ensaio ELISA no qual se acopla, a um par antígeno-anticorpo, um segundo anticorpo marcado (o qual absorve na região do visível e assim pode ser facialmente detectado). As Figuras 7 e 8 mostram os espectros na região do ultravioleta-visível para o PHEMA puro (Figura 7) e para a blenda Pani-PHEMA com 20\% em massa de Pani (Figura 8). Pode-se observar, na comparação dos espectros nas Figuras 7 e 8, que as amostras submetidas à imobilização (ensaio ELISA) têm alteração sensível entre compri- 


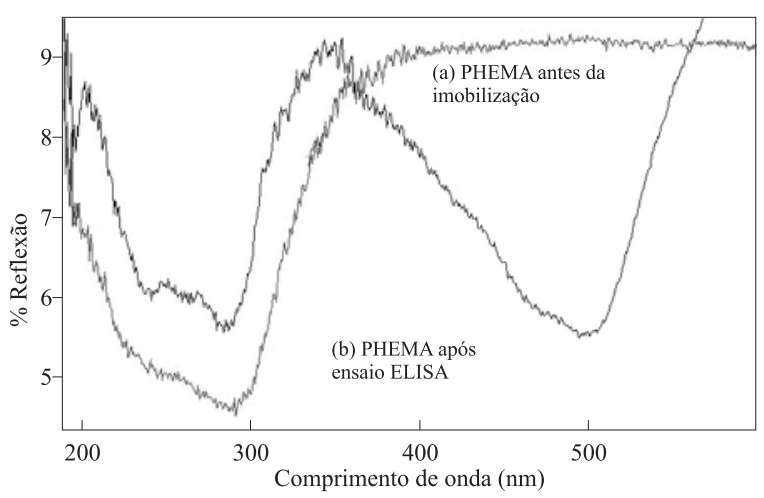

Figura 7. Espectro na região do ultravioleta-visível de PHEMA antes (a) e após (b) imobilização de proteínas relacionadas com o veneno do escorpião Tytius Serrulatus.

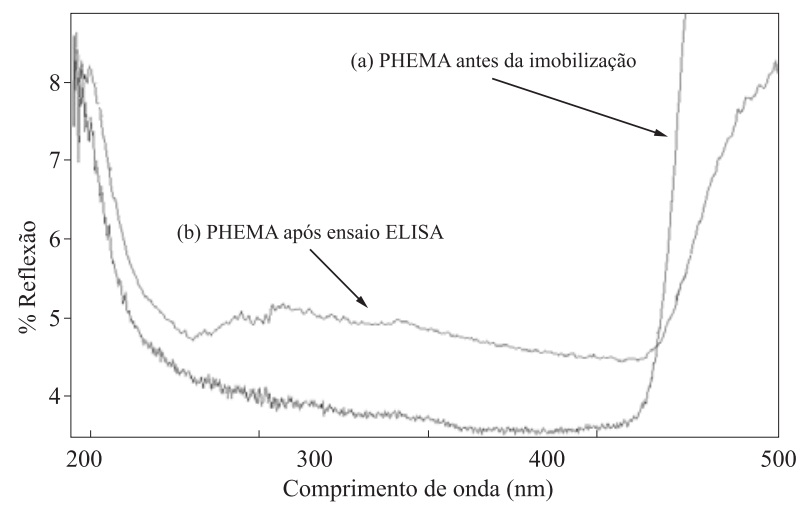

Figura 8. Espectro na região do ultravioleta-visível da blenda PHEMA$20 \%$ Pani antes (a) e após (b) imobilização de proteínas relacionadas com o veneno do escorpião Tytius Serrulatus.

mentos de onda 200 e $250 \mathrm{~nm}$, região esta na qual absorvem vários grupamentos químicos presentes em aminoácidos como tiol, amina, aromáticos, entre outros. Fica, assim, indicada a presença de proteínas (antígenos e anticorpos) imobilizadas nos materiais associadas ao veneno do escorpião Tytius Serrulatus. Na região de comprimento de onda entre 300 e $400 \mathrm{~nm}$, que é a região na qual o anticorpo marcado com peroxidade (ensaio ELISA) absorve, houve também notável alteração nos espectros antes e após a imobilização tanto para o PHEMA puro (Figura 7), como para blenda Pani-PHEMA (Figura 8). Tais resultados mostram que não só a imobilização como também a ligação específica antígeno-anticorpo, relacionados com o veneno do escorpião Tytius Serrulatus, foram alcançadas com sucesso. Assim, não foi notada alteração na bioatividade de antígenos relacionados com o veneno de escorpião, quando da imobilização destes nos polímeros, demonstrando que os materiais testados e o processo de imobilização usado permitem a confecção de substratos aptos a incorporarem sem danificação as proteínas relacionadas com veneno do escorpião Tytius Serrulatus.

\section{Conclusões}

Blendas poliméricas baseadas na combinação de polianilina e poli(metacrilato de hidroxietila) foram sintetizadas com composições variando entre 0 a $100 \%$ de Pani. A utilização de agente reticulante MDI se mostrou adequada para produção de redes semi-interpenetrantes entre os dois polímeros. A partir da variação das concentrações do agente reticulante e de Pani nas blendas foi possível a produção de materiais com amplas faixa de condutividade elétrica e capacidade de inchamento, quando em solução aquosa. A blenda com $20 \%$ em massa de Pani e $5 \%$ em massa de agente reticulante exibiu condutividade elétrica e capacidade de inchamento consideradas adequadas para viabilizar a combinação de dois aspectos essenciais para a eficiência de um biossensor: capacidade de interagir com macromoléculas através do inchamento da matriz e elevada condutividade elétrica para permitir o monitoramento de eventos biológicos. Proteínas relacionadas com o veneno do escorpião Tytius Serrulatus foram imobilizadas com sucesso em blendas Pani-PHEMA através do inchamento dessas em soluções contendo as proteínas. Antígenos associados ao veneno do escorpião mantiveram sua bioatividade mesmo após imobilização, como demonstrado a partir da interação específica deste antígeno com o seu anticorpo. Assim sendo, a blenda formada pela combinação de PHEMA e Pani apresenta uma série de aspectos favoráveis que motivam o teste desses materiais como base na formulação de um biossensor, capaz, por exemplo, de ser usada na detecção e quantificação de antígenos relacionados com o veneno de escorpião.

\section{Agradecimentos}

Os autores agradecem ao CNPq e FAPEMIG pelo apoio financeiro ao projeto de pesquisa.

\section{Referências Bibliográficas}

1. Collingst, A†., Caruso F. Rep. Prog. Phys 60 p.1397-1445 (1997)

2. Luppa, P. Clinica Chimica Acta 314 p.1 - 26 (2001)

3. Brahim, S. Biosensors \& Bioeletronics, 17 p.53 - 59 (2002)

4. Lian Cen, K.G.. Biosensors \& Bioeletronics, 18 p.363-374 (2003)

5. Revelo, M.P. Toxicon, 34 p.1119 - 1125 (1996)

6. Olortegui, C. Toxicon, 32 p.1649 - 1656 (1994)

7. Gerard, M. Biosensors \& Bioeletronics, 17 p.345 - 359 (2002)

8. Sergeyeva, T. Sensors and Actuors B, 34 p.283 -288 (1996)

9. Duncan, A. C. European Polymer Journal, 37 p.1821 - 1826 (2001)

10. McDiarmid, A.G.; Chiang, J.D.; Richeter, A.F.; Somasiri, N.L.D.; Epstein, A.J. Conducting Polymers, in: Alcacer, L., cap 1, Reidel Pub (ed.), Dordrecht Holland, (1987).

11. Lowry, O. R. Journal Biology Chemisry, 193 p.265 - 275 (1951)

12. Banerjee P.; Mandal, B. M. Macromolecules 28 p.3949 (1995).

13. Stauffer, D. Introduction to Percolation theory, Taylor and Francis, London 1985.

14. Yang, C.Y. Synthetic Metal, 53 p.293 (1993).

Enviado: 03/11/03

Reenviado: 25/03/04

Aprovado: 23/04/04 